\title{
Metakimosphere no.2
}

Performance, July 22-25, 2015, Madrid (Spain) Remembered somewhat later, Sept. 14 (England)

Johannes Birringer

Brunel University London, United Kingdom

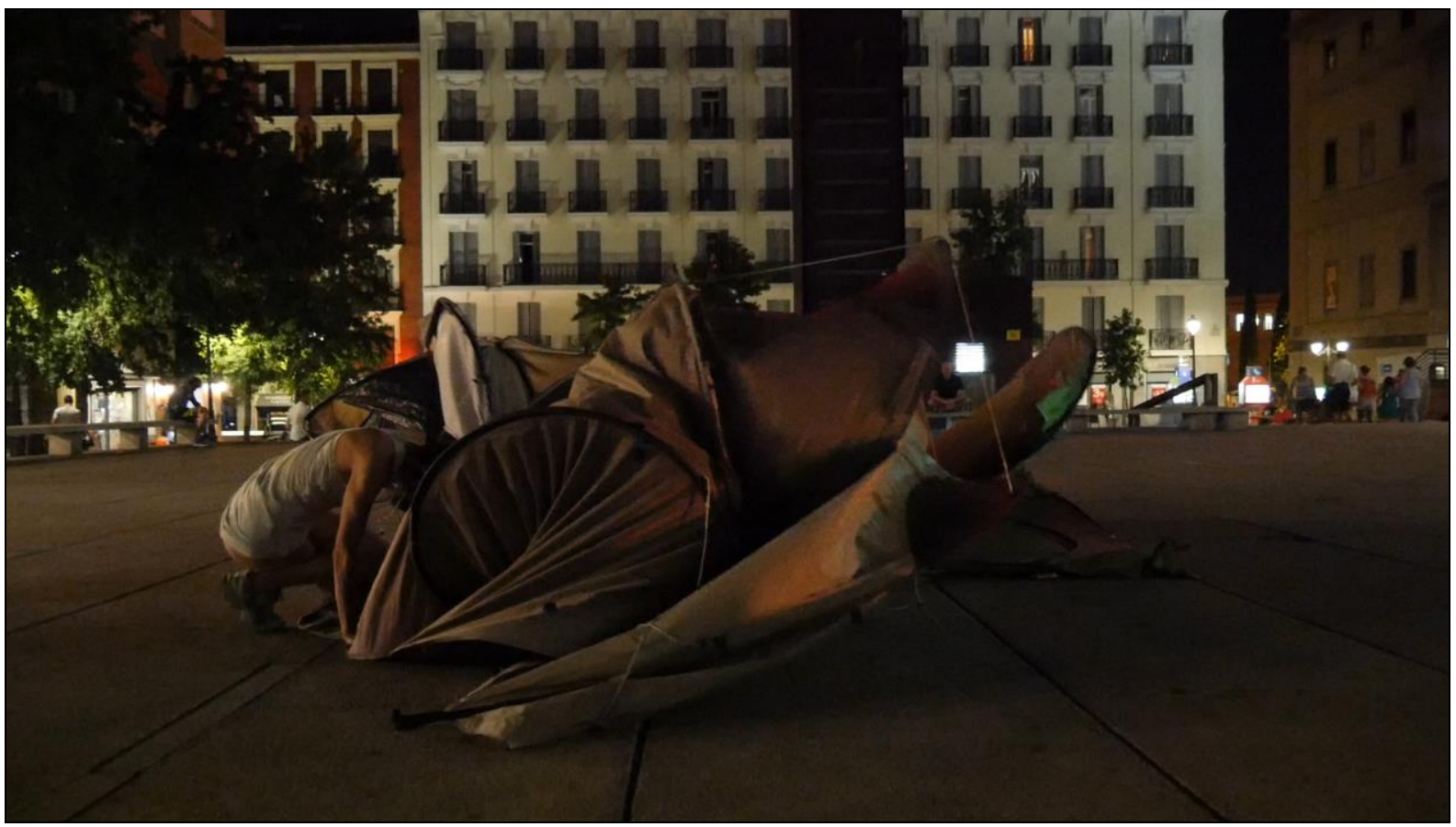

Photo credit: DAP-Lab

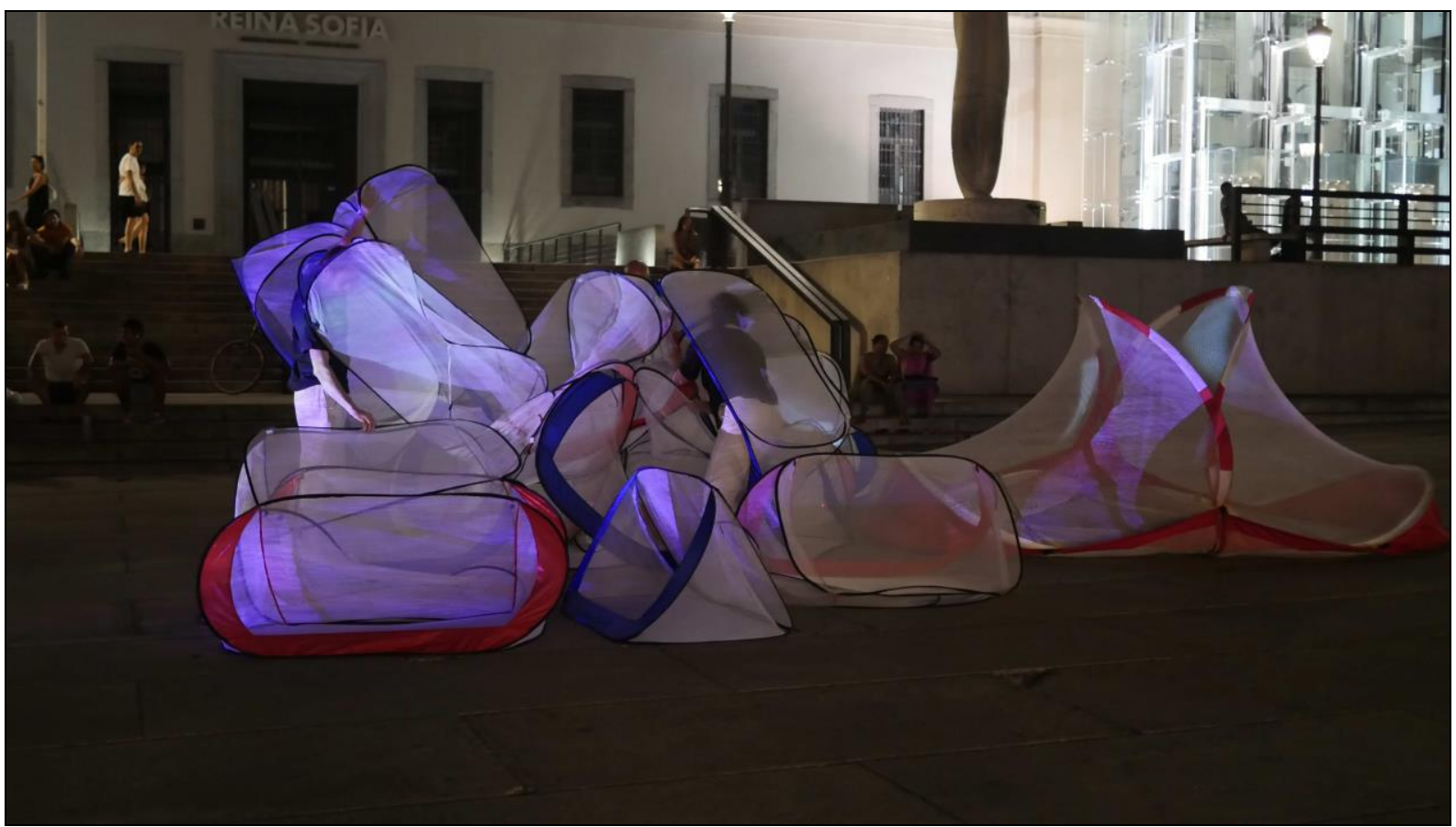

Photo credit: DAP-Lab 
The refugees had not settled yet and no one knew the extent of the great migration and how it would sweep across Europe and beyond; the transmigrations had pushed into full view however, a hovering violent exposure of vulnerability. It was a hot summer, the days seemed longer. Audiences appeared out of nowhere and suddenly the auditorium was full of people. A short while later, all was dark, and action had moved out into urban streets and squares. Tent-like structures waltzed across pavement. It seemed as if these temporary shelters, our tents, were moved by invisible bodies.

Metakimosphere no. 2 was the DAP-Lab's second performance-installation built to test the idea how performance materials produce atmospheres, how tents can be redesigned into wearables. The first instantiation, in London, happened much earlier, and all I remember is a poem sent to me by an audience member a few weeks later. How can one build a new prototype on the resonance of a poem?

But resonance is a form of memory, inside our bodily architectures. And kimosphere (kinetic atmosphere) I imagined to be a Gefüblsraum, created for dancers and visitors exploring/sensing a very intimate sonic space which envelops and acts as a suspended transparent veil and encumbrance - hiding-revealing, allowing light and "graphic writing" to flow through, affording variable tactile orientations, colors, tones, shapes, positions, and sensations, affecting bodies forming a single-body inside a cocoon-like gauze texture or multiple-bodies that become discombobulated. Later, one would perhaps remember traces left on the body, interior and peripheral sensations, curvilinear, intestinal tremors.

But first I remember the breath... this small sound coming from within, a tiny speaker attached to fibres hear the floor. How to think such a wearable architecture - gauze that spreads out across the floors, breathes, a wall at the other end that moves towards us, changing color and responding to our behavior, the audience huddled around, watching how the dancer in the origami dress unfolds and folds back her body as the wall begins to move and make strange motoric noises? The motors must be what moves the pulleys and strings over there... we here, on the other side of the marionette space?

Then I remember the white gauze beginning to heave; vaguely one makes out contours of a body that is crouched, slowly, slowly rising until the fabric of body's elongated dress stretches all across, now a third dancer appears from nowhere, gently stepping through crouched audience, with a hand that is like a bird's beak, and from the beakhand a voice of a shaman sounds, high pitched chant evoking spirits (in 한국어), I recall the guttural sounds of this man, but his voice delicately transforms into gesture - the woman dancer now becoming a shaman herself pointing her beak to the audience, jerking the hand backward and forward, slashing across air, while the body under the gauze has meanwhile stretched space. Tiny particles dance on the floor, activated by sensors that capture fleeting moments of $3 \mathrm{D}$ contours of the woman in origami dress. Of course there are cameras, sensor, the whole space is under surveillance...Weathering and wearing, I sense slow space, and halted movement, we are caught somehow... perhaps I project as weakening of clear definition what I cannot put in logical language. 


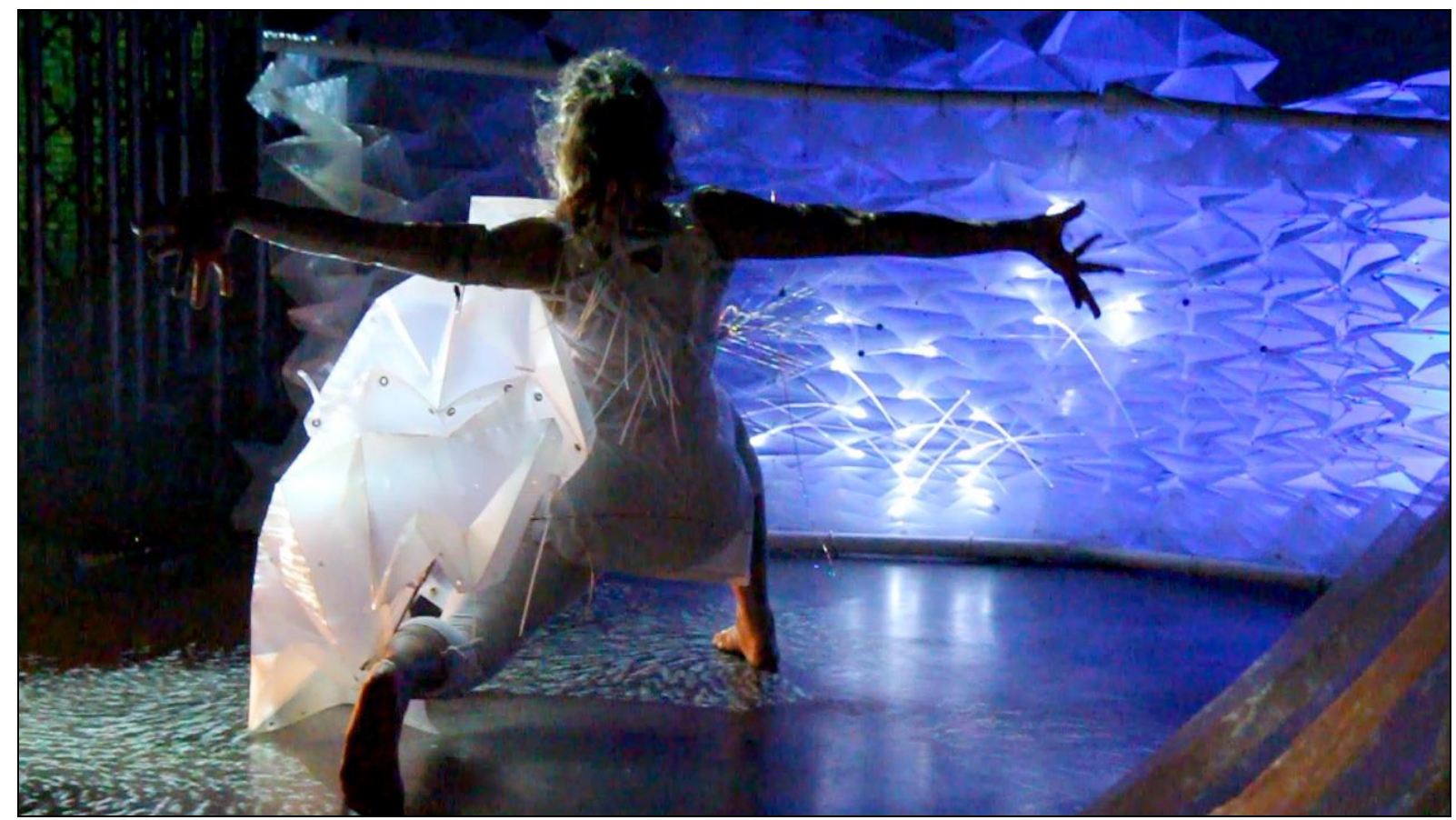

Photo credit: DAP-Lab

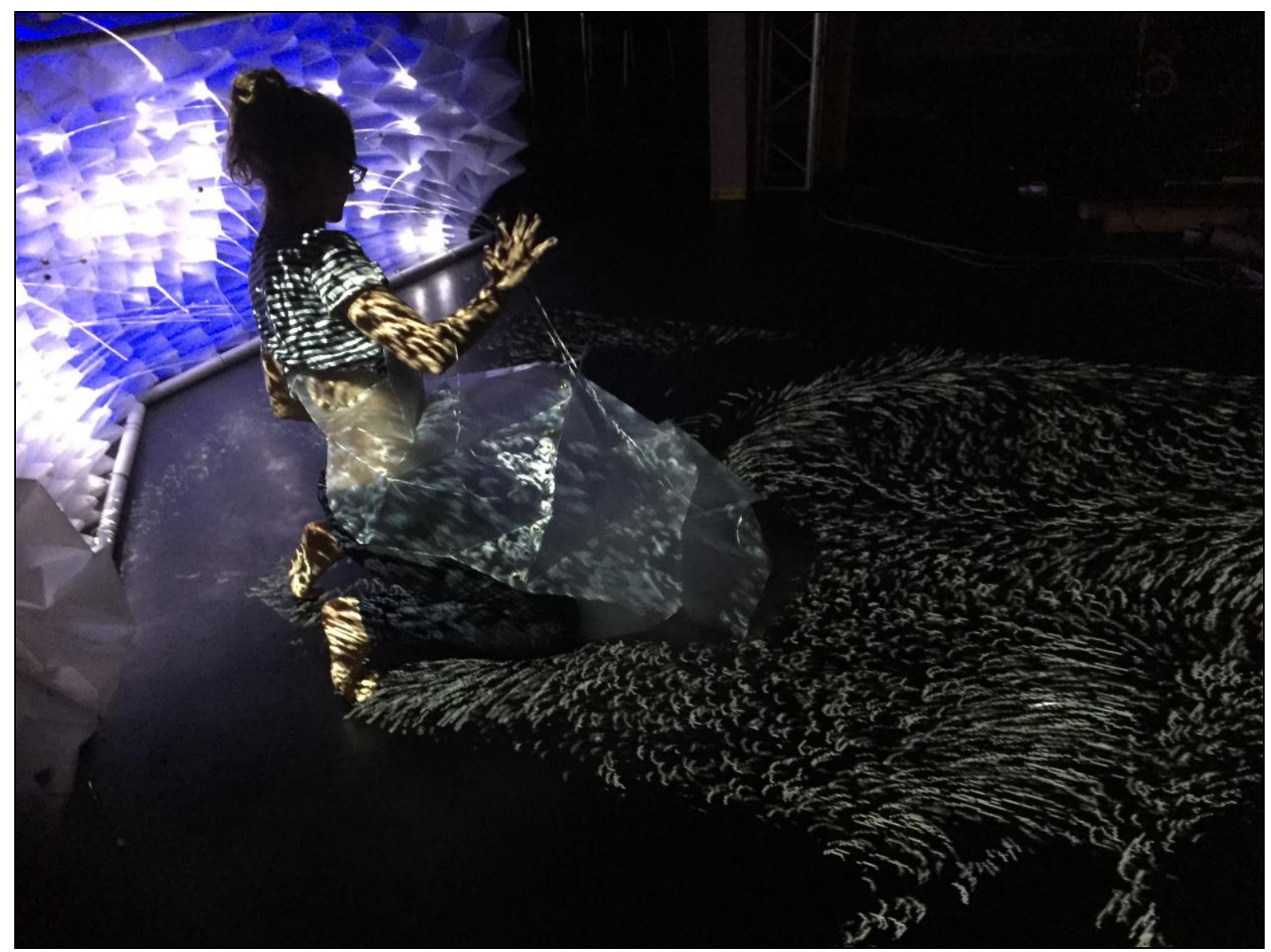

Photo credit: DAP-Lab 
Spectres hang

In translucent wombs, Drifting in amniotic sacks

Of white noise

That fizzes and shifts.

Cobwebs cling to pale Limbs forming papery shrouds,

The absinthe light moves In and out

With each rattled aspiration,

A simultaneous cry Of death and sex.

Then the shamanic voice seems suddenly dispersed, bouncing off walls and corners and slowly disappearing, like an airplane that withers off into far distance leaving behind only a soft, disintegrating vapor trail, sublimely simple telekinetic trace, of sensations that had been spatially discharged.

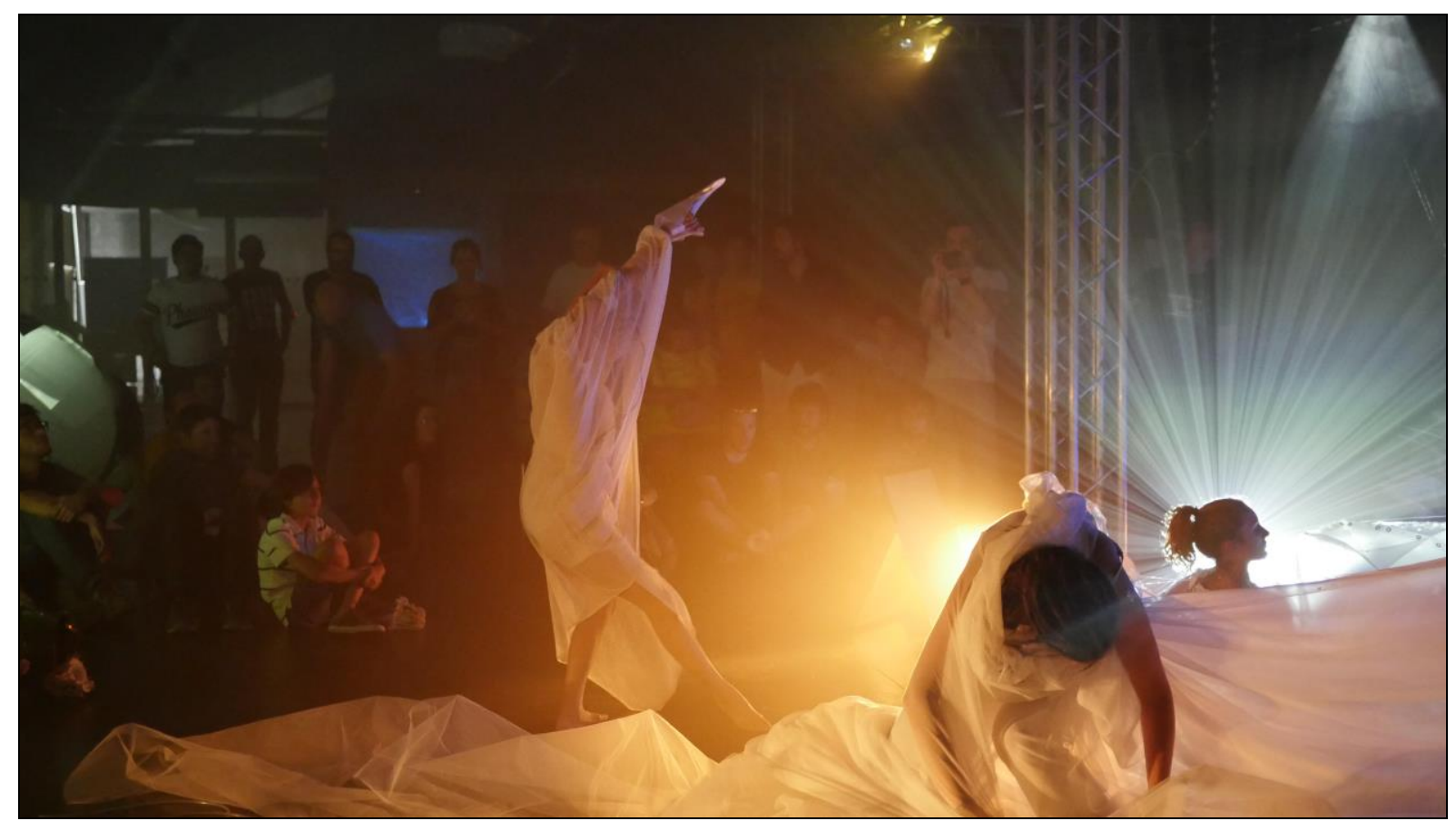

Photo credit: DAP-Lab 


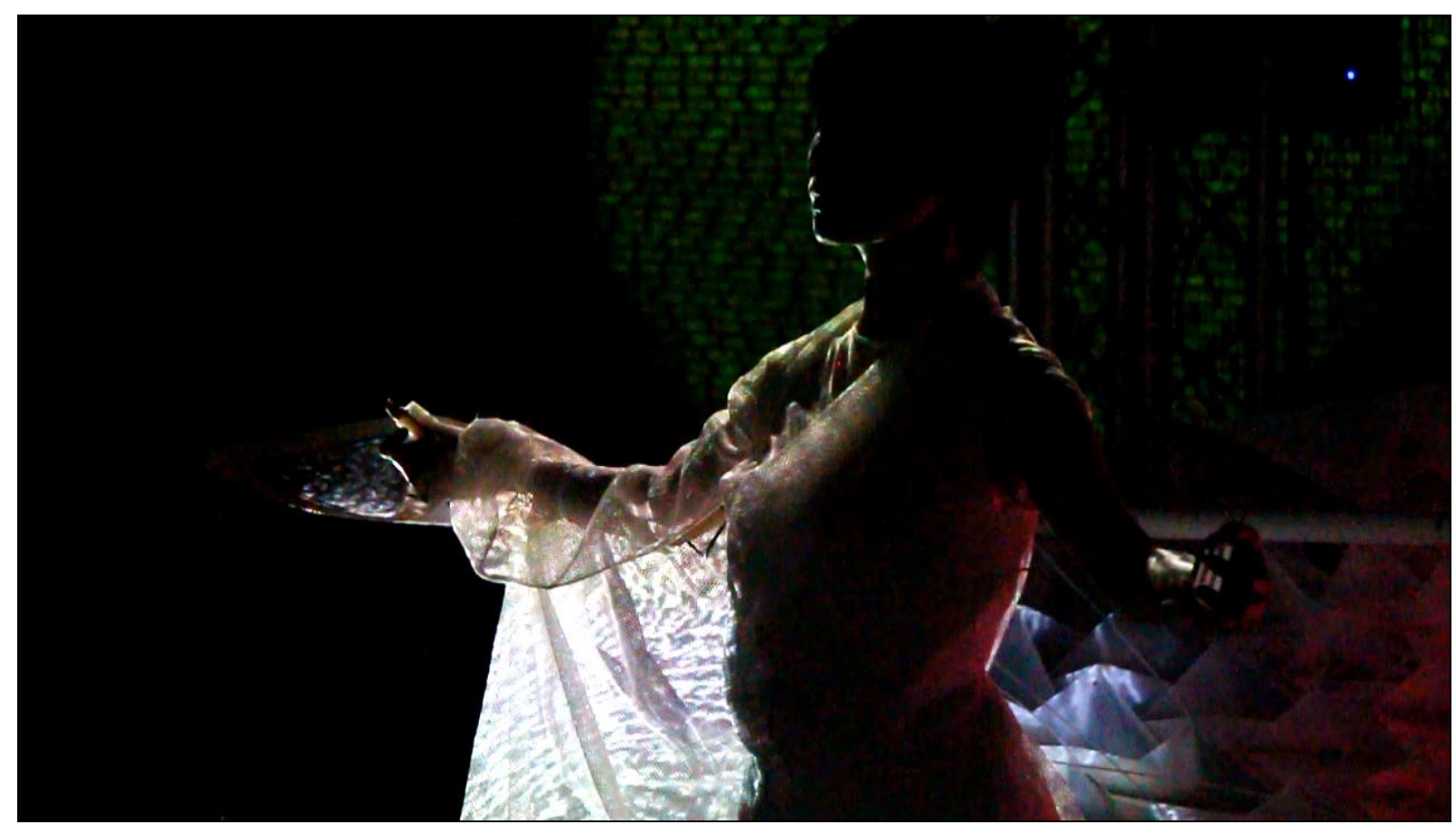

Photo credit: DAP-Lab

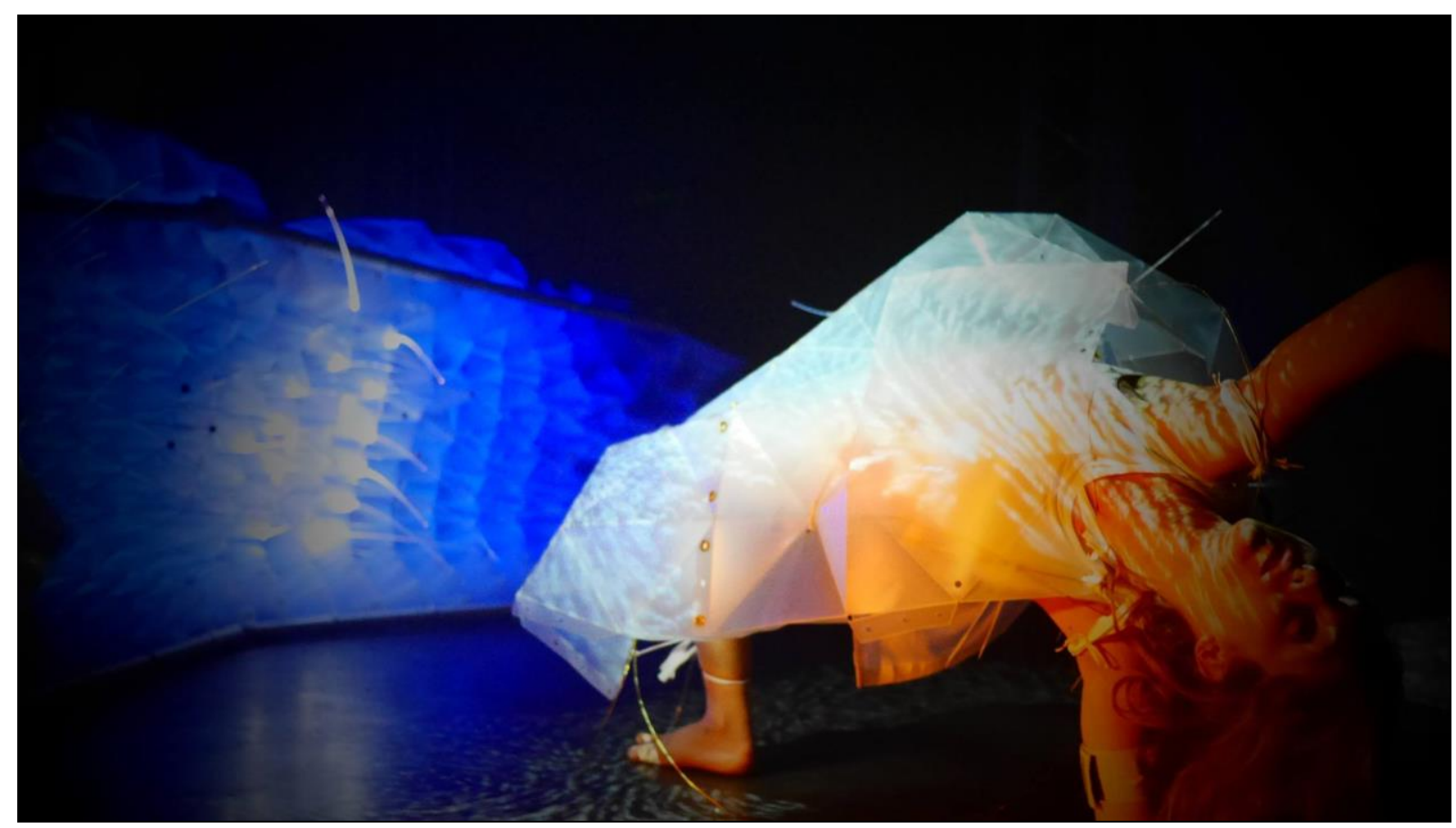

Photo credit: DAP-Lab 


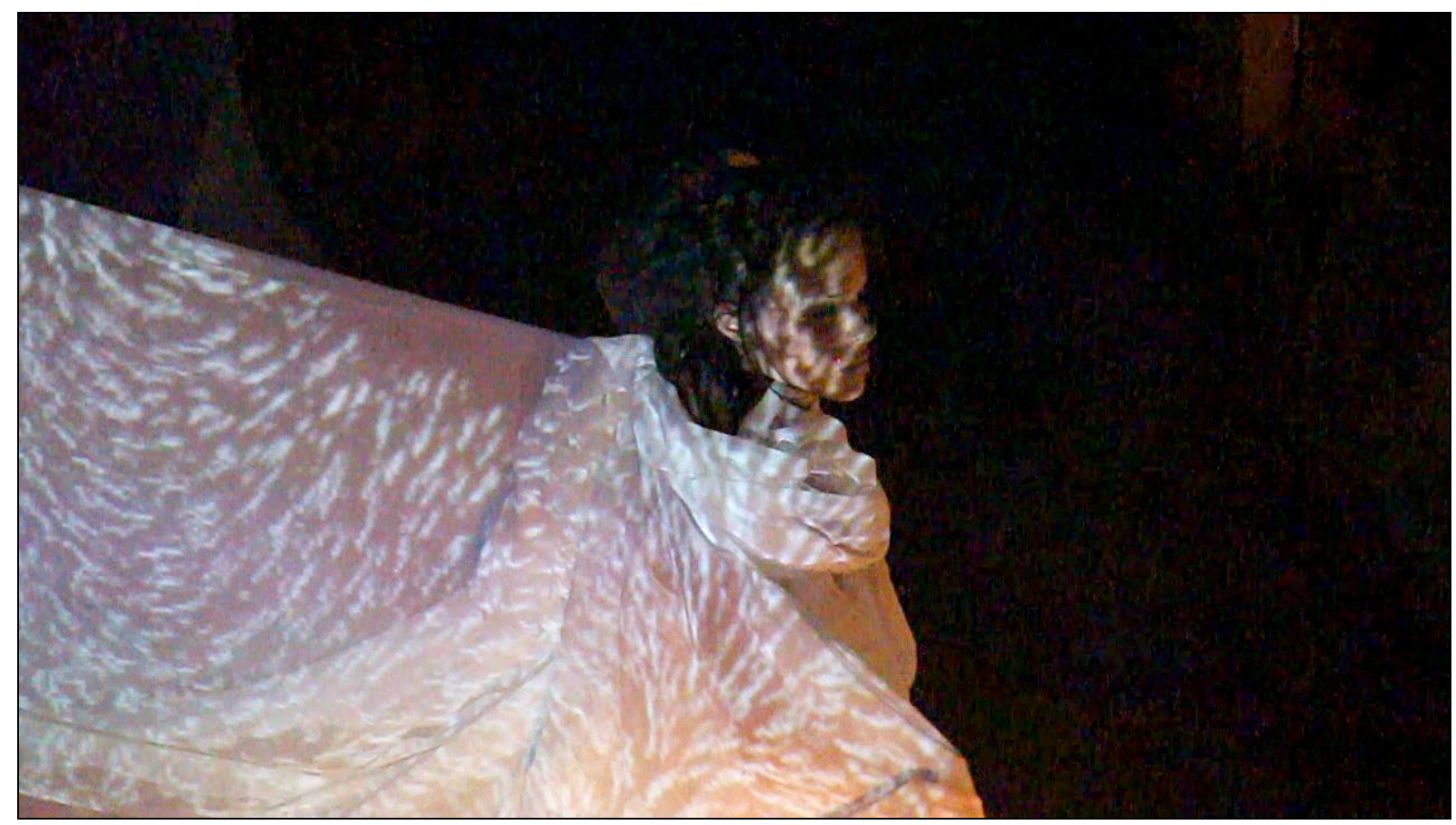

Photo credit: DAP-Lab

\section{Credits}

DAP-Lab's performance is directed by choreographer/media artist Johannes Birringer and fashion designer/art director Michèle Danjoux. The international ensemble participating in the Madrid presentations included Vanessa Michielon (choreographer/dancer), Miri Lee (choreographer/dancer), Azzie McCutcheon (choreographer/dancer), Jonathan Reus (electronic artist), and Christopher Bishop (network/software artist).

Project website: http://people.brunel.ac.uk/dap/metakimosphere.html Photos: (C) DAP-Lab

Poem (extract) (C) 2015 courtesy of Emma Filtness 